Article

\title{
Exploring the Use of Cognitive Behavioural Therapy (CBT) for Reducing Rider Stress and Stress-Related Anxiety, Anger, and Worry
}

\author{
Kristen Fernández-Medina * and Nick Reed \\ TRL, Crowthorne House, Nine Mile Ride, Wokingham RG40 3GA, UK; nreed@trl.co.uk \\ * Correspondence: kfernandez@trl.co.uk; Tel.: +44-(0)1344-770058 \\ Academic Editor: Teresa Senserrick \\ Received: 29 April 2016; Accepted: 9 October 2016; Published: 20 October 2016
}

\begin{abstract}
Stress can have serious implications on road safety and evidence suggests that it could lead to increases in driving errors, lapses, and even crashes. Motorcyclists are a vulnerable road user group, and lapses in attention and risky behaviours resulting from stress could increase the risk of collision. However, few safety interventions for reducing stress have been developed and evaluated, especially in motorcyclists. The purpose of this research was to develop and pilot a Cognitive Behavioural Therapy (CBT) course for the treatment of rider stress. Five motorcyclists experiencing a range of life and work stressors completed the CBT course between January and March 2015. Findings from the Driver Stress Inventory and Driver Behaviour Questionnaire showed positive trends in the overall reduction of rider stress traits, such as aggression, thrill seeking, and dislike of riding. Qualitative data showed that participants engaged well with the intervention and believed it had aided them in their riding-related stress. Although these results are promising, the results warrant further investigation in order to validate $\mathrm{CBT}$ as a viable means of reducing the collision risk both for this already vulnerable road user group and other driver categories.
\end{abstract}

Keywords: stress; motorcyclists; Cognitive Behavioural Therapy; intervention; road safety

\section{Introduction}

Health and Safety Executive (HSE) statistics from the United Kingdom show that in 2014/15 stress accounted for $35 \%$ of all work-related illness reported and $43 \%$ of all working days lost due to illness [1]. The effects of stress (whether work- or life-related) on health and wellbeing are well evidenced and can even trigger short- and long-term physiological changes [2]. It is, therefore, likely that such changes could affect the performance of everyday tasks, such as driving.

\subsection{Stress and Road Safety}

A study examining individual differences in collision risk highlighted that transient factors such as stress could play an important role in collision causation [3]. Retrospective data showed that up to $80 \%$ of drivers involved in fatal crashes were under serious stress before a crash (compared with up to $18 \%$ of a control group) (Finch \& Smith, 1971, as cited in [3]). More recent work has also shown that transient stress states (or 'state stress', defined as stress relating to specific life situations or events [4]) can have negative consequences on road safety; for example, a study by Rowden and colleagues found that stress related to general life hassles (including self-reported work-related stress and life stressors) was associated with increases in driving errors, violations, and lapses. This study involved a sample of 247 employees aged 22-69 years old [5]. Similarly, work by Legarde and colleagues [6] and Legree and colleagues [7] also found that life events were associated with an increase in traffic collisions; 
Legree et al.'s work reported that heightened stress and emotional state prior to the collision were predictive of driver at-fault status.

Although previous research has been able to find associations between stress and collision risk, less is known about how other factors mediate this relationship. As work by Legree and colleagues suggests [7], the driver's state of mind can have an impact on road risk. This is consistent with contemporary models of driver behaviour [8]. Thus, the internal state of the driver is also an important element to consider in relation to driver stress and, as suggested by Golding (1983), research relating to traffic collisions should focus on "the variety of values, emotions, stresses and perceptions that drivers bring with them when they get behind the wheel of the car" (Golding, 1983, as cited in [9], p. 196).

Trait stress (stress from factors that reside within the individual [4]) has been the subject of research by authors such as Matthews and colleagues (e.g., [10-12]) and has shown that personality characteristics may also influence driver stress by increasing the individual's vulnerability to stress and/or behavioural outcomes related to it [9]. Critically, traits such as anger, anxiety, and thrill seeking have been found to relate to driver stress (e.g., [10]); moreover, these personality traits have also been associated with increases in risky driving behaviours and/or collisions even in the absence of stress (e.g., [13-15]).

\subsection{Interventions for Driving and/or Riding Stress}

Despite the possible detrimental effect of stress on road users, few interventions are available for those facing difficulties on the road due to stress or stress-related anxiety, anger, or worry. Cognitive Behavioural Therapy (CBT) has been explored within the context of road safety and research has shown that CBT can also be effective in improving the mindset of car drivers in relation to dangerous on-road behaviours [16-18].

CBT is an evidence-based talking therapy based on the premise that behaviours that are counter-productive or harmful are a result of maladaptive thinking patterns. The aim of the therapy is to identify and modify these patterns by encouraging insight and providing effective thought management skills [19]. Since its development, it has been used to treat a wide range of conditions such as depression, anxiety, obsessive-compulsive disorder, bulimia nervosa, anger, and chronic pain [20,21]. It has been extensively researched and established as a fundamental tool in psychological treatment.

A study conducted by Najeeb [16] investigated the effects of a four-day (eight hours a day) CBT course on driver road safety attitudes on a sample of bus drivers $(n=200)$ aged 35 to 55 in India. Participants were selected from a pool of drivers (matched on various psychological variables) and randomly assigned to a control or experimental group $(n=100$ each). Participants in the experimental group were introduced to a course based on CBT methods to target a wide range of non-clinical issues directly related to driving, including speeding, unrealistic optimism (about drivers' own ability), risk perception, and human limitations (including the effects of alcohol and limitations of cognition, attention, and perception). The outcome measures included a driver personality questionnaire (measuring affective, cognitive, and sensory motor domains of driver behaviour) and a driver training assessment scale, which measures attitudinal change toward speeding, driving ability, and risk. Comparison of the control and experimental group showed that the intervention yielded a significant positive difference in the safety attitudes of drivers. The therapy was also found to be well received by drivers.

Strom and colleagues also evaluated the use of group CBT with a sample of nine male military veterans who reported aggressive and risky driving behaviours [17]. Participants took part in eight group sessions facilitated by two psychologists. Of those completing the treatment, and according to a reliable change criterion (a measure used to define clinically significant change in therapy outcomes with a 'dysfunctional population') generated for the outcome measures, five participants demonstrated a reliable change in risky driving, and four demonstrated a reliable change in anger. Eight of the nine participants showed high levels of satisfaction with the treatment, and seven reported they would recommend it to a friend [17]. 
Previous work in this area is not without its limitations, including the lack of objective measures of behavioural or attitudinal change, lack of a control group, and the inclusion of drivers with psychological comorbidities (i.e., [17]). In addition, although not a research limitation per se, the lack of methodological consistency between research studies has limited the comparability of the available findings. Not only does this limitation relate to the outcome measures employed but also to the CBT programme structure employed (for example, Strom and colleagues [17] delivered their intervention over eight weeks and Najeeb [16] delivered his 'training' over four sessions).

Nonetheless, years of research have supported the use of CBT to address a wide range of conditions ranging in type and severity. This, along with findings relating to the use of CBT with car drivers, shows that there is potential to develop an intervention to assist stressed road users who may be at heightened risk of being involved in a collision.

\subsection{Motorcyclist Risk}

Most research on the use of CBT or CBT methods as a road safety intervention has focused on the risk to drivers (including company cars, vans, or buses). However other road user groups, such as motorcyclists, already face increased risk of being involved in a collision; U.K. data showed that in 2014 motorcyclists comprised only about $1 \%$ of all road traffic but $19 \%$ of all road casualties [22].

Riders also face distinctive risks when on the road. Particularly, exposure to factors such as extreme weather conditions, shared road space, and conspicuity can not only increase risk of being involved in a collision $[23,24]$ but may increase susceptibility to on-road stressors. Issues around conspicuity in particular have been raised by riders as important safety concerns when on the road [25], and it is a well-known fact that riders are overrepresented in collisions at junctions where other road users may fail to appropriately assess their approach speed or may fail to see them completely [24], thus raising additional possible stressors for riders on their journeys.

There is also evidence that motorcyclists experience the road environment differently to car drivers, supporting the need for tailored interventions for this road user group. For example, research has previously identified that motorcyclists may be willing to accept a higher level of risk, either by viewing it as a 'calculated' risk necessary for safe riding or as part of the 'thrill-seeking' adventure riding provides [25-27].

Given the growing body of research relating to the role of psychological states on increasing risk to road users, it is vital to ensure that there are effective interventions available that can help road users cope with stress and its effect on riding.

\subsection{Study Aims}

The initial aim of this study was to develop a brief Cognitive Behavioural Therapy (CBT) intervention for motorcyclists who had experienced riding difficulties due to stress and/or stress-related anxiety, anger, or worry. We also sought to develop a method to evaluate the intervention that could make up for the limitations of previous research. The second aim was to undertake a short-term evaluation of the effectiveness of the CBT programme with a small sample of motorcyclists.

\section{Materials and Methods}

A multi-method design was employed in this study. This involved collection of both quantitative (e.g., questionnaire data) and qualitative data from a small number of research participants $(n=5)$.

As this is a relatively novel use of the CBT intervention, case studies were also employed to allow a more detailed assessment of participant's experience with the CBT programme.

\subsection{Participant Selection}

In order to evaluate the effectiveness of the intervention, it was important to ensure that it was provided to the appropriate audience, that is, riders who: 
- $\quad$ were affected by stress and who could identify (and report) clear signs of this;

- regularly ride a motorbike; and

- $\quad$ are exposed to life stressors that may be affecting their riding behaviour, as demonstrated by self-reported risky riding.

A screening survey was used to select the final sample. The survey was publicised (as a web link) through a variety of channels, including local and national motorcycle clubs and associations, social media, and the Transport Research Laboratory's (TRL) participant database (TRL is a United Kingdom-based private research organization providing independent and impartial research, consultancy, testing, and certification for all aspects of transport).

The TRL database includes details on key demographics (such as age, gender, and driving experience) of over 2500 local drivers and riders in the Berkshire area. The aim of the database is to provide TRL researchers with a pool of potential participants who are within accessible distance to TRL's headquarters and who have consented to be contacted for research purposes.

\subsubsection{Frequency of Riding}

We sought participants who reported at least some weekly exposure to riding. Although the ideal participants were those whose primary mode of transport was the motorcycle, given the already narrow inclusion criteria (as will be discussed in Sections 2.1.2 and 2.1.3, below), riders who undertook more than three journeys on their motorbike in a week were shortlisted. This was operationally defined as the number of one-way journeys the participant undertook in a week (i.e., a journey from home to work and back again constituted two journeys).

It was believed that riders who undertook various journeys in a week would be more likely to experience stressors related to being on the road (time pressure, congestion); they would also have the most opportunity to interact with other traffic and thus would be more likely to experience stressful riding situations during the course of the study.

The research was limited by time of year (November to March) due to operational constraints; therefore, only participants who undertook motorbike journeys all year round (and in any weather) were invited to take part in the research.

\subsubsection{Exposure to Life Stressors}

The self-reported exposure to life stressors was subdivided into two categories, which could be broadly characterised by stress and its effect on riding.

1 The existence of a life stressor(s) (i.e., is the participant experiencing identifiable stressors in their daily life in the past six months?).

2 Effect on riding behaviour or riding style (i.e., is any stressor having a perceived effect on their riding behaviour?).

The latter was of particular importance as many riders that were contacted for recruitment purposes felt that riding was in fact a stress release. Although this does not exclude the presence of risky behaviour while riding, it was beyond the scope of the present study to evaluate perceived versus actual riding behaviour and, as such, participants who were unable to identify life stressors were not shortlisted for the pilot.

\subsubsection{Pre-Existing Psychological Conditions}

In addition to a set of specific inclusion criteria for participants, exclusion criteria were also developed together with the CBT practitioner relating to pre-existing psychological conditions, particularly post-traumatic stress disorder (PTSD).

The decision to exclude participants based on any reported psychological difficulties (or any indicators of such) was taken because the existence of other mental health conditions could potentially 
mediate the presence of stress or risk-taking behaviours, and hence the CBT for stress may not have been appropriate (or beneficial) for these respondents.

In addition, it was advised by the CBT practitioner that those diagnosed and treated for a mental health condition in the previous six months may still be undergoing a period of consolidation (of previous therapy), which could also bias the results of the intervention on trial.

\subsection{CBT Sessions}

CBT directly targeting motorcycle rider stress is not currently standard practice. A new session protocol therefore had to be devised for the purpose of this study.

\subsubsection{Programme Development}

A CBT protocol was developed specifically for the research with the combined expertise of the CBT practitioner and TRL experts in motorcyclist safety. The course was developed based on a stress management CBT protocol and the materials associated with it, as suggested by the qualified practitioner.

The broad steps taken for developing the intervention included the following:

1 Initial scoping-discussions between TRL and the CBT practitioner to establish the course purpose, contents, duration, and any limitations.

2 Establishing the desired outcomes-the outcomes of the intervention were re-focused such that its primary purpose was to improve road-related behaviours that could be mediated by stress and/or stress-related anxiety, anger or worry. As such, stress-related symptoms were generally to be discussed within the context of its effects on the individual's on-road behaviours.

3 Development of CBT course contents-this involved the modification of the existing protocol for stress management and integrating road safety elements and materials to the course syllabus. Including:

a. Development of a road safety information sheet (specifically for motorcyclists) for the course's psychoeducation element.

b. Re-development of 'homework' materials and weekly log (later discussed as the 'rider $\left.\log ^{\prime}\right)$ - this was to become the primary discussion point for weekly sessions and was modified to include on-road incidents/stressors and encourage thinking within this context.

The resulting course was a structured six-week rider stress programme. It was believed that, as participants would be screened so as to ensure no obvious comorbid conditions were present, this version of the intervention would allow appropriate interaction with participants and ensure commitment was possible for the duration of the intervention.

\subsubsection{Programme Structure and Contents}

Table 1 provides an overview of the CBT course structure developed for the research. The same protocol was used with all participants; however, the particular issues discussed were based on the participant's personal experiences and desired behavioural outcomes (within the established course purpose). These were established in the first session, and goals for the intervention were agreed between the participant and practitioner.

The sessions included weekly assignments to be completed by participants. These were provided in order to help participants think about the discussion with the practitioner and keep track of weekly goals. The assignments were the key points of discussion during the weekly sessions. 
Table 1. CBT session components.

\begin{tabular}{|c|c|c|c|}
\hline Session & Title/Focus & Session Goals & Homework \\
\hline Session 1 & Introduction & $\begin{array}{l}\text { The practitioner and participant worked } \\
\text { together to assess the identified stressor(s) and } \\
\text { the participant's emotional state and to identify } \\
\text { rider behaviours of interest. This part of the } \\
\text { intervention included psycho-education } \\
\text { (developed specifically to integrate } \\
\text { rider-specific risk and road safety education) } \\
\text { and the development of mutual goals. }\end{array}$ & $\begin{array}{ll}\text { - } & \text { Stress leaflet } \\
\text { - } & \text { Rider log }\end{array}$ \\
\hline Session 2 & $\begin{array}{l}\text { Taking care of } \\
\text { yourself }\end{array}$ & $\begin{array}{l}\text { Introduction to relaxation techniques and } \\
\text { discussion about health behaviours } \\
\text { (sleep, exercise). }\end{array}$ & 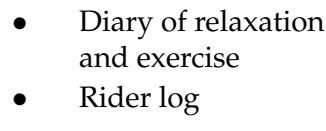 \\
\hline Session 3 & $\begin{array}{l}\text { Managing } \\
\text { behaviour }\end{array}$ & $\begin{array}{l}\text { The practitioner trained the participant in } \\
\text { relaxation and coping strategies. } \\
\text { The discussions also included the identification } \\
\text { of 'triggers' (i.e., on-road stressors) of unsafe } \\
\text { riding behaviours and how to manage these. }\end{array}$ & $\begin{array}{ll}\text { - } & \text { Problem } \\
\text { solving exercise } \\
\text { - } \quad \text { Rider log }\end{array}$ \\
\hline Session 4 & Thoughts & Continuation of the above strategies. & - $\quad$ Rider log \\
\hline Session 5 & Managing worry & $\begin{array}{l}\text { Methods for managing worry, with a focus on } \\
\text { on-road behaviours. }\end{array}$ & $\begin{array}{ll}\text { - } & \text { Worry log } \\
\text { - } & \text { Rider log }\end{array}$ \\
\hline Session 6 & $\begin{array}{l}\text { Consolidation } \\
\text { and relapse } \\
\text { prevention }\end{array}$ & $\begin{array}{l}\text { The practitioner and participant explored how } \\
\text { to put the elements discussed into practice, } \\
\text { consolidation, and discussion of } \\
\text { long-term goals. }\end{array}$ & $\begin{array}{l}\text { - Consolidation } \\
\text { worksheet }\end{array}$ \\
\hline
\end{tabular}

\subsubsection{Delivering the CBT}

A risk assessment was undertaken prior to the start of the research in order to ensure the safety of the practitioner and the participants. This covered personal safety (for practitioner and participants), emergency procedures (e.g., fire), lone working, and late working safety procedures. Ethical approval was also sought before the start of the study.

Once all the ethical and safety requirements were in place, and prior to the first session, participants were sent an information package by post. This contained a detailed account of what they could expect from the sessions, the required time commitment (including the requirement to complete 'homework' assignments), and details about data collection and protection by TRL. The package also included information about the practitioner (e.g., name, qualifications, etc.) and two questionnaires to be completed before they attended their initial session (see Section 2.3.1.).

Once the programme commenced, participants attended a weekly (sometimes, once every two weeks) face-to-face session for the duration of the program. The sessions were one hour in length and only the participant and the qualified practitioner were present for each session (one-on-one). All sessions were held in a private room at TRL's Crowthorne House offices on weekends between January and March 2015. Although sessions were usually held on a weekly basis, issues with availability meant that some participants had up to two weeks between some of their sessions.

The sessions were audio recorded and the practitioner developed notes about each session, the participant, and key discussion points. In order to preserve the participants' confidentiality, these detailed notes were not shared with TRL. Instead, the practitioner provided the research team with a case summary for each participant.

After the final session, participants were provided with a final package of questionnaires to complete and post back to TRL. 
Participants received a total of $£ 60$ for taking part in the research. This was divided up between a small amount after each session (£5), and then $£ 30$ upon completion of the final questionnaires.

\subsection{Data Collection}

Questionnaire data was collected by post on two occasions:

1 Pre-intervention-one week before the participant's first session with the practitioner.

2 Post-intervention - one to three weeks after the participant's last (sixth) session with the practitioner.

Due to time constraints, one participant completed the post-intervention questionnaire before his final session.

Qualitative data regarding participants' riding behaviours was collected on a weekly basis (rider log); after completion of the intervention a general programme feedback form was also completed by participants. These are described in more detail in the sections below.

\subsubsection{Quantitative Data}

Participants completed two previously validated self-report questionnaires, the Driver Stress Inventory (DSI) and the Driver Behaviour Questionnaire (DBQ). Items on both the DBQ and DSI were re-worded in order to fit the motorcyclist sample involved in the study.

DSI

The DSI [28] has been widely used in driver stress research, and has been found to measure a number of driver stress traits such as aggression ('AGG'), dislike of driving ('DIS'), thrill seeking ('TS'), and hazard monitoring ('HM'). Hazard monitoring, unlike the other subscales, is believed to be a 'protective' factor, as it has been related to positive outcomes such as higher levels of psychological wellbeing $[5,28]$. Lower scores on the AGG, DIS, and TS are indicative of safer attitudes toward driving; the opposite is true for the HM subscale. In order to facilitate the interpretation of findings, for the purpose of this research, the scores for the HM subscale have been reversed. Therefore, lower scores on all the DSI subscales represent safer attitudes toward driving.

DSI items are assessed using a visual analogue scale (ranging from 0 to 10); for each item participants were asked to indicate their relative level of agreement to the end point statements by indicating a position along a continuous line between two end-points.

In previous driver stress research (e.g., $[5,12,28])$, the four DSI subscales included in this study have been found to correlate with dangerous road behaviours such as speeding, traffic violations, driver errors, and accident involvement.

The DSI also contains a fatigue subscale, but this was not used for the purpose of the study. This was mainly due to the full version (e.g., fatigue items) of the DSI not being available to the research team.

\section{DBQ}

The DBQ [29] contains 50 items scored on a five-point Likert scale ranging from 'Never' (score of 0 ) to 'Nearly all the time' (score of 5). Participants were instructed to indicate their level of agreement or disagreement with a given statement.

The DBQ is also widely used within road safety. A recent meta-analysis of 174 studies (involving over 45,000 respondents) employing the DBQ showed that DBQ errors and violations are significant predictors of self-reported collisions [30]. In addition, DBQ violations have been found to correlate directly with on-road simulated measures of driving behaviour (such as speed choice) [31]; other research has also showed that both errors and violations are associated with high levels of stress experienced while on the road [32].

For the purpose of this study, a shortened version of the DBQ was used [33]. This version contained 26 items: nine items covered violations, two items for unintentional violations, and 15 items for lapses. 


\subsubsection{Qualitative Data}

Rider Log

Participants were asked to keep a weekly rider log. This allowed them to record specific events that had acted as stressors (or 'triggers') in a particular week; participants were also asked to note how these situations were managed. This allowed participants to record events soon after they had occurred (thus minimising issues with retrospective recall of events).

The log encouraged participants to think about the situations and break them down into the thoughts and feelings experienced, their behavioural response to the situation, and any physiological symptoms identified.

This information was also used during sessions to encourage discussion (particularly in relation to 'triggers') and pinpoint any specific issues that could be worked on for the following week. When possible, it was also used to complement the questionnaire data and provided case study analysis of improvements made week-on-week.

\section{Qualitative Feedback}

At the end of the programme, participants were provided with a short questionnaire in order to gain their feedback regarding their participation in the sessions. The questionnaire assessed their motivations for taking part as well as their perception of any changes in their thoughts and/or behaviours as a result of the intervention.

\section{Case Summaries}

The CBT practitioner provided a case summary report for each participant. The report included weekly discussion points and milestones reported by participants.

\subsection{Data Analysis}

The exploratory nature of this study resulted in a small sample size being available for analysis. Thus only raw scores were assessed; no inferential statistical tests were run on these data due to the obvious sample size limitations.

Quantitative data, collected using the DSI and DBQ, were used to compare participants' scores on both these measures between pre- and post-intervention (one to three weeks after).

Qualitative data (i.e., weekly rider logs, a case summary, and participant feedback) were analysed to assess emerging themes. Rider logs and case summaries were also used to support the questionnaire data, and, where possible, to provide examples of reported changes in strategies used to cope with stressful events.

\subsection{Ethics}

The study approach was evaluated and approved by the TRL ethics committee. As the topic area covered by this work was of a potentially sensitive nature, it was agreed with participants and the CBT practitioner that TRL would only have access to rider logs and the case summaries provided by the practitioner at the end of the programme. Any other materials, including homework assignments and other materials, would be kept confidential by the practitioner.

\section{Results}

\subsection{Sample Characteristics}

Table 2 details the characteristics of the sample participants. 
Table 2. Summary of participant characteristics.

\begin{tabular}{cclcccc}
\hline $\begin{array}{c}\text { Participant } \\
\text { No. }\end{array}$ & Age & Gender & $\begin{array}{c}\text { Journeys Per Week } \\
\text { (Motorcycle) }\end{array}$ & $\begin{array}{c}\text { Average Mileage } \\
\text { (Per Year) }\end{array}$ & $\begin{array}{c}\text { Riding } \\
\text { Experience }\end{array}$ & Type of Bike \\
\hline 1 & 32 & Male & $6-10$ & 6000 & $\begin{array}{c}\text { More than } \\
10 \text { years }\end{array}$ & $\begin{array}{c}\text { Sports } \\
\text { tourer }\end{array}$ \\
\hline 2 & 37 & Male & 10 & 7000 & $3-5$ years & $\begin{array}{c}\text { Adventure } \\
\text { sport }\end{array}$ \\
\hline 3 & 32 & Male & 10 & 10,000 & $3-5$ years & $\begin{array}{c}\text { Naked } \\
\text { bike }\end{array}$ \\
\hline 5 & 46 & Female & 8 & 9500 & $3-5$ years & $\begin{array}{c}\text { Adventure } \\
\text { Sport }\end{array}$ \\
\hline & 59 & Male & 12 & 9000 & $\begin{array}{c}\text { More than } \\
10 \text { years }\end{array}$ & $\begin{array}{c}\text { Adventure } \\
\text { sport }\end{array}$ \\
\hline
\end{tabular}

The youngest participants were 32 years old and the oldest was 59 years. All participants reported being employed at the time the research was undertaken.

Participants in the sample reported travelling an average of 8583 miles a year by motorcycle; they also reported undertaking between seven and 10 trips per week. Most of the journeys undertaken were for commuting purposes. Only one of the five participants reported having experienced an injury collision in the previous year. Two others reported having been involved in at least one injury collision previously in their lifetime. All participants reported that their primary mode of transport was a motorcycle.

All of the categories in the table above are bikes over $125 \mathrm{cc}^{\prime} \mathrm{s}$ and tend to differ in terms of properties such as torque, comfort, fuel economy, fairings, windscreens, fuel capacity, and bike weight.

\subsection{Overall Results}

\subsubsection{DSI and DBQ}

Table 3 shows the raw scores of the DSI and DBQ at pre- and post-intervention for the study participants. The scores show a trend toward a small reduction in all four DSI subscale scores. This means that participants seemed to show safer attitudes toward riding and better hazard monitoring after they had undertaken the CBT intervention.

Table 3. Individual DSI and DBQ for participants at pre- and post-intervention assessment.

\begin{tabular}{ccccccccc}
\hline & \multicolumn{9}{c}{ DSI } & \multicolumn{2}{c}{ DBQ } \\
\hline $\begin{array}{c}\text { Participant } \\
\text { No. }\end{array}$ & $\begin{array}{c}\text { Time } \\
\text { Point }\end{array}$ & DIS & AGG & TS & HM & $\begin{array}{c}\text { Unintentional } \\
\text { Violations }\end{array}$ & Violations & $\begin{array}{c}\text { Slips and } \\
\text { Lapses }\end{array}$ \\
\hline \multirow{2}{*}{ Participant 1 } & Pre & 3.35 & 6.86 & 5.93 & 3.53 & 2.50 & 1.56 & 1.53 \\
& Post & 3.56 & 5.06 & 4.38 & 2.67 & 2.00 & .89 & 0.73 \\
\hline \multirow{2}{*}{ Participant 2 } & Pre & 6.01 & 4.64 & 0.55 & 3.17 & 0.50 & 0.22 & 0.33 \\
& Post & 5.95 & 3.22 & 1.61 & 2.56 & 0.50 & 0.33 & 0.53 \\
\hline \multirow{2}{*}{ Participant 3 } & Pre & 5.23 & 3.56 & 4.71 & 2.79 & 0.50 & 0.89 & 0.80 \\
& Post & 3.65 & 3.75 & 4.73 & 2.43 & 1.00 & 0.56 & 0.40 \\
\hline \multirow{2}{*}{ Participant 4 } & Pre & 4.74 & 5.83 & 3.78 & 4.09 & 2.50 & 0.89 & 0.80 \\
& Post & 3.89 & 3.93 & 2.88 & 2.41 & 1.50 & 0.33 & 0.60 \\
\hline \multirow{2}{*}{ Participant 5 } & Pre & 3.68 & 2.67 & 0.64 & 2.89 & 2.00 & 0.22 & 0.67 \\
& Post & 2.43 & 2.18 & 0.14 & 2.81 & 2.00 & 0.22 & 0.47 \\
\hline
\end{tabular}

The largest difference observed was for the aggression subscale, where participants were found to show up to a 1.9-point reduction on their attitudes from pre- to post-intervention. 
Responses to DBQ also showed a small trend in overall reduction in mean scores on all three DBQ subscales (Table 3). Although scores on the DBQ subscales are relatively low even at pre- intervention, the observed difference in scores post-intervention is consistent with the direction that is associated with lower collision risk.

\subsubsection{Qualitative Feedback}

When asked to provide feedback relating to their experience engaging with the intervention, all participants reported having a positive experience with the programme and the practitioner. Participants also reported a series of changes in their thought process and/or behaviours as a result of having taken part in the intervention.

For example, one participant reported taking part in the intervention made her more self-aware of her behaviours.

"I've learnt triggers which affect/stress me, and some of them were not things I had realised before."-Female, 46 years old

Others reported increased insight toward their own thoughts and behaviours; this increased insight included the belief that the programme had helped them improve their mindset regarding their riding and other road users.

"I don't have a strong prejudice any more about other road users."-Male, 37 years old

"[I am] less likely to be aggressive"-Male, 32 years old (1)

Some participants also reported feeling generally more relaxed, and being able to cope more effectively with stressful situations.

"It has been very helpful; I can now shut out all of my work problems the minute I leave work.

This means that I am much more relaxed on the way home ... "-Male, 59 years old

"I've started to act on warnings I recognise, rather than just ignore them like before, i.e., if I'm too close to the vehicle in front, drop back"-Female, 46 years old

One participant characterised his feelings prior to undertaking the intervention as "I would not say I have ever been someone who agrees these kind of methods work"; however, upon completion of the CBT intervention, the same participant reported having a positive experience.

"I enjoyed the sessions and honestly believe they have changed the way I ride for the better."-Male, 32 years old (2)

\subsection{Case Studies}

In the following section, we will detail results from a subsample of participants that exhibited the most substantial differences from the pre to post evaluation with relation to the two quantitative measures (DSI and DBQ) and the weekly rider logs.

Data for each case were broken down into four subsections:

1 Participant profile- provides general information about age, gender, life stressors and dangerous riding behaviours reported before undertaking the intervention.

2 Session breakdown - provides information about the unique elements of the sessions (tailored to the individual) and the main areas identified for improvement within the programme. This data was provided by the practitioner in the participant's case summary.

3 Quantitative data-this provides data comparing scores on the DSI and DBQ, at pre- and post- intervention assessment.

4 Rider log-provides examples of 'triggers' (road traffic interactions) that participants identified through their weekly logs. These provided a snapshot of attitudinal and behavioural elements reported by participants throughout the intervention. 


\subsubsection{Participant 1}

\section{Participant Profile}

Participant 1 reported three life stressors: work, financial concerns, and dealing with multiple responsibilities.

Participant 1 also believed stress was affecting his riding behaviours. He reported that in the past six months he had been feeling:

- Increased frustration with other drivers and/or riders;

- Increased anger toward other drivers and/or riders;

- Increased risk taking while riding, including speeding, overtaking when unsafe to do so, or riding under conditions you would not normally;

- Increases in number of near-collisions, or collisions with other road users.

He completed the CBT intervention between November 2014 and January 2015.

\section{Session Breakdown}

The sessions for Participant 1 were focused on helping the participant with a combination of lifestyle changes (exercising and eating habits) and promoting a better understanding of self, particularly relating to triggers of aggressive and anxious riding.

Two key learning areas were identified for this participant: 'letting go' of other road users' behaviours, and helping the participant to be more aware of his mood and surroundings when riding.

\section{Quantitative Data}

Participant 1's data showed that he exhibited up to a 1.80 point score reduction from pre-intervention to post-intervention assessment. The largest change was in relation to the aggression subscale of the DSI (pre-intervention average score $=6.86$; post-intervention average score $=5.06$ ), as shown in Figure 1a.

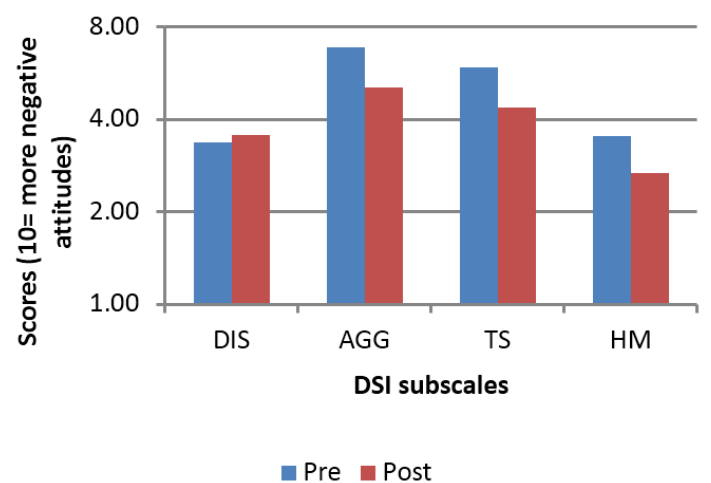

(a)

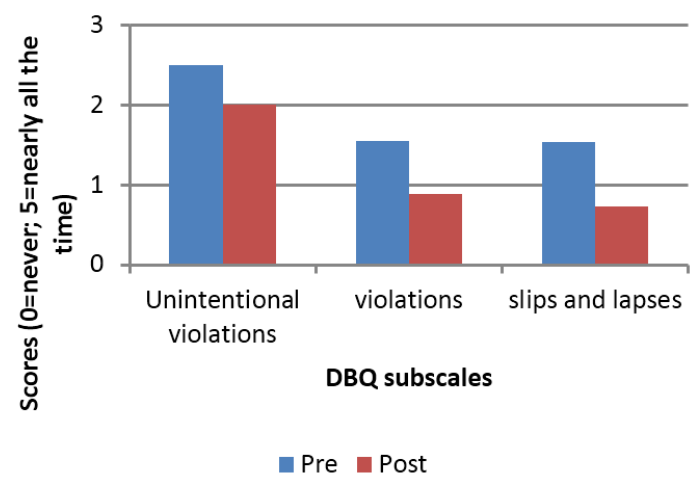

(b)

Figure 1. (a) Line chart showing DSI scores for Participant 1, pre- and post- CBT intervention; (b) line chart showing DBQ scores for Participant 1, pre- and post- CBT intervention.

Figure 1a also shows a tendency toward improvement (i.e., lower scores) in the average scores for subscales relating to thrill-seeking and improved hazard monitoring at the post assessment. The dislike of riding score increased slightly, though this change was very minor (change of 0.27 points). Moreover, the participant reported that he had not been affected by feelings of insecurity or anxiety while riding, which may also account for the relatively stable score in this subscale.

DBQ scores showed a similar trend with slips and lapses exhibiting the largest difference in scores from pre-intervention to post-intervention (from an average score of 1.33 at pre-intervention to 0.67 at 
post-intervention). This said, all scores on subscales were lower at the post-intervention assessment (when compared to the pre-intervention time point) (Figure 1b).

\section{Rider Log}

Participant 1 reported a number of incidents he had experienced while riding his motorcycle. These were recorded on the rider log and were used to discuss 'triggers', set the individualised goals, and assess any progress made.

Table 4 relates to an incident early on in the intervention process (after session 2). As evidenced by the information provided, the participant's remarks communicate feelings of anger and anxiety. It also provides insight into the participant's immediate behaviour in response to the event.

Table 4. Participant 1 incident report, session 2.

\begin{tabular}{ll}
\hline Session 2 Log & Participant's Responses \\
\hline Situation & $\begin{array}{l}\text { pulled out from the side (the vehicle), locked up brakes, and had to go } \\
\text { round her (driver of another vehicle) }\end{array}$ \\
\hline Thoughts & "I don't want someone who will hit me behind me" \\
\hline Feelings & Anger and anxiety \\
\hline Behavioural response & $\begin{array}{l}\text { Overtook three cars in front of her, to make space between us; rode } \\
\text { faster for } 1 / 2 \text { mile }\end{array}$ \\
\hline
\end{tabular}

Table 5 provides an event recorded after the fourth session (when the practitioner trained the participant in relaxation and coping strategies and 'triggers' had been identified). The information provided by the participant shows that he was able to apply the techniques provided and thus his reported behavioural response to a similar road traffic event was safer.

Table 5. Participant 1 incident report, session 4.

\begin{tabular}{ll}
\hline Session 4 Log & Participant's Responses \\
\hline Situation & Someone pulled out-left no gap, slow driver \\
\hline Thoughts & "Let him get on with it" \\
\hline Feelings & Calm \\
\hline Behavioural response & Pulled back, let driver get on with it \\
\hline Reflection after incident & $\begin{array}{l}\text { "Pulling back is a better thing to do"-less dangerous, costs less in petrol, } \\
\text { is worse when mood is bad, less shouting/muttering }\end{array}$ \\
\hline
\end{tabular}

\subsubsection{Participant 4}

\section{Participant Profile}

Participant 4 reported work as her main stressor, but also believed stress was affecting her riding behaviours. She reported that in the past six months she had been feeling:

- Increased frustration with other drivers and/or riders;

- Increased anger toward other drivers and/or riders;

- Increases in riding and driving errors or lapses (e.g., finding yourself accidentally driving in the wrong direction).

Participant 4 undertook the CBT intervention between January and February 2015. 


\section{Session Breakdown}

The sessions for Participant 4 were focused on helping the participant to 'look after herself' (the participant had been dealing with health issues), and helping her to manage work-related stress, which was also affecting aspects of her riding such as mood and concentration.

Two main learning areas were identified: 'letting go' of other road users' mistakes (when "other people don't follow 'my rules'"'), and helping the participant to improve concentration while riding (i.e., not thinking about work or past negative experiences).

\section{Quantitative Data}

Similar to Participant 1, Participant 4's quantitative data show a positive shift in attitudes on the DSI. The biggest improvement for this participant was also in the aggression subscale, where she exhibited a 1.9 point change from pre-intervention to post-intervention (from 5.83 to 3.93) (Figure 2a).

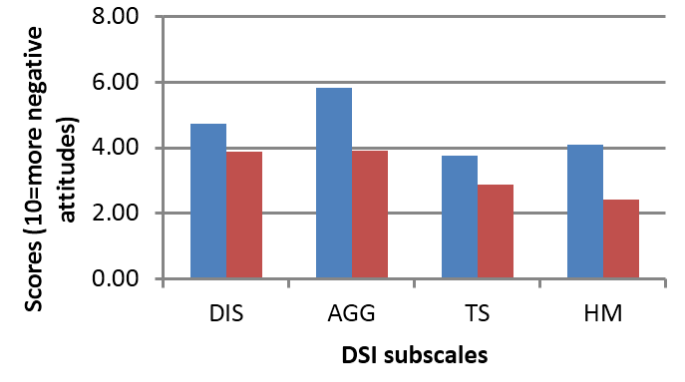

- Pre $\square$ Post

(b)

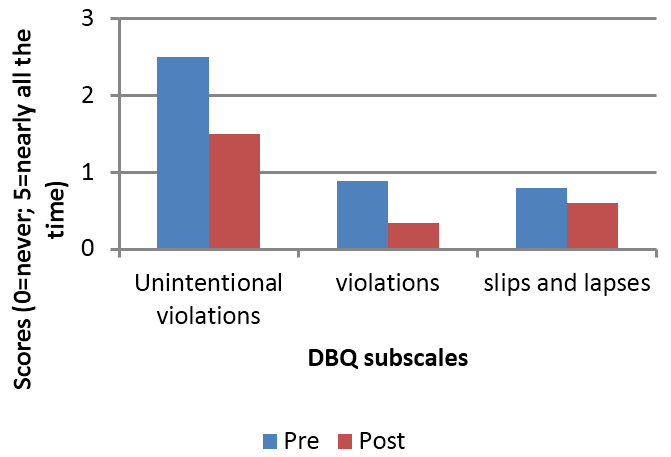

(c)

Figure 2. (a) Line chart showing DSI scores for Participant 4, pre- and post- CBT intervention; (b) line chart showing DBQ scores for Participant 4, pre- and post- CBT intervention.

Similarly, her hazard monitoring (as measured by DSI) also showed a 1.7 point change in scores from pre-intervention to post-intervention (from 4.09 to 2.41). This corresponds well with details of the session breakdown, where 'concentration' was identified as one of the key areas of improvement by the practitioner and participant alike.

The DBQ violations subscale showed the largest difference for this participant (from 0.89 at pre-intervention to 0.33 at post-intervention) (Figure $2 b$ ).

\section{Rider Log}

Participant 4 reported two particular on-road events of interest. Table 6 details an event that occurred at the initial stages of the programme (after session 2, while the participant and practitioner were still in the process of understanding the issues faced and how to best resolve these). The event related to the participant's vehicle being damaged and the participant reported feelings of anger.

Table 6. Participant 4 incident report, session 2.

\begin{tabular}{ll}
\hline Session 2 Log & Participant's Responses \\
\hline Situation & Someone parked too close and damaged car \\
\hline Thoughts & $\begin{array}{l}\text { "Why is my door damaged? I did my level best to park properly. I wouldn't do it } \\
\text { that way, so why are others doing it to me?" }\end{array}$ \\
\hline Feelings & Anger \\
\hline Behavioural response & Wanted to let anger out, but knew she couldn't direct it at anyone \\
\hline Physiology & None identified \\
\hline
\end{tabular}


Table 7 shows an event logged by the participant after the fifth session (this is when the participant has received the key training in coping strategies and triggers have been better understood). The event was a near-crash, and although the participant reported that she felt anxious and/or threatened, she also recognised that she was able to 'let go' of the incident much more quickly.

Table 7. Participant 4 incident report, session 5.

\begin{tabular}{ll}
\hline Session 5 Log & Participant's Responses \\
\hline Situation & Example of a 'near miss' the Friday before session 5 \\
\hline Thoughts & "You idiot, you didn't even see me" \\
\hline Feelings & Sense of threat/anxiety \\
\hline Behavioural response & $\begin{array}{l}\text { Reacted safely and quickly. Didn't linger over the incident, didn't } \\
\text { mention it to husband afterwards, didn't overreact }\end{array}$ \\
\hline Physiology & Initial heart jump but no other sensations \\
\hline Reflection after incident & $\begin{array}{l}\text { "Felt a lot calmer, did not feel annoyed for long after incident, let it go more } \\
\text { easily even though it was a close call." }\end{array}$ \\
\hline
\end{tabular}

\subsection{Summary of Additional Cases}

The section above presents the findings for two of the participants who provided the most complete data, particularly in terms of completing the weekly rider log. As all exercises were voluntary (to a certain degree), not all participants provided weekly qualitative data relating to their riding behaviours and experiences. This section provides a summary of the remaining three participants.

As shown in Table 3, most participants had a tendency toward slightly decreased scores at post-intervention, when compared to their pre-intervention scores. Participant 2 exhibited a higher score on the thrill-seeking subscale of the DSI at post-intervention (around a 1-point difference from pre-intervention to post-intervention). Otherwise, the differences in scores seemed somewhat mixed, with some (e.g., Participant 3) exhibiting larger changes (e.g., a 1.58-point change from pre-intervention to post-intervention on the 'Dislike' scale); other scores, however, remained relatively stable.

Qualitative data for Participants 2, 3, and 5 were less complete as participants did not always report a weekly road-related event. In addition, Participant 3 exhibited more deeply rooted difficulties (relating to his recent collision event) and, as such, clear progression week-on-week was not always evident in terms of the self-reported behavioural responses to situations. However, this could be due to a number of reasons and as such the tables below present some examples of reported on-road behaviours, triggers, and responses while undertaking the CBT course (Tables 8-10).

Table 8. Participant 2 incident report, session 5.

\begin{tabular}{ll}
\hline Session 5 Log & Participant's Responses \\
\hline Situation & $\begin{array}{l}\text { Went out for a ride with colleague. Was feeling very anxious before } \\
\text { undertaking the ride. }\end{array}$ \\
\hline Thoughts & Anxious, worried \\
\hline Feelings & $\begin{array}{l}\text { Later, he reported feeling more at ease_- “[My] colleague respected speed } \\
\text { limits and [I] didn't feel under pressure” }\end{array}$ \\
\hline Behavioural response & None identified \\
\hline Physiology & None identified \\
\hline Reflection after incident & $\begin{array}{l}\text { One of his main triggers was other drivers making mistakes; he notes } \\
\text { that thinking of individuals who have made a mistake as a potential } \\
\text { Nobel prize winner (one of the strategies provided by the practitioner) } \\
\text { has really helped him to see other road users as individuals. }\end{array}$ \\
\hline
\end{tabular}


Table 9. Participant 3 incident report, session 5.

\begin{tabular}{ll}
\hline Session $\mathbf{5}$ Log & Participant's Responses \\
\hline Situation & $\begin{array}{l}\text { While driving, another road user made a rude hand gesture } \\
\text { to the participant. }\end{array}$ \\
\hline Thoughts & "If I react, it will only cause more problems." \\
\hline Feelings & OK, calm \\
\hline Behavioural response & Gave him space, let him go \\
\hline Physiology & None identified \\
\hline Reflection after incident & "Letting it go was [the] easier option for me." \\
\hline
\end{tabular}

Table 10. Participant 5 incident report, session 5.

\begin{tabular}{ll}
\hline Session 5 Log & Participant's Responses \\
\hline Situation & "Total idiot pulled out in front of me" \\
Thoughts & None identified \\
Feelings & Relaxed, not bothered, calm \\
Behavioural response & Let him go \\
Physiology & More relaxed \\
Reflection after incident & Noticed a difference in being able to let things go more easily. \\
\hline
\end{tabular}

\section{Discussion}

Stress has been shown to increase road risk, including the risk of being involved in a collision. Despite only representing a very small proportion of all vehicles on the road, motorcyclists are at a higher risk of being involved in a collision than car drivers. Given the consistent findings showing the negative effect of stress on road safety, this vulnerable road user group should be considered when developing interventions to help reduce road traffic risk.

CBT has been shown to be effective in a broad range of contexts, and has recently been applied to counter drivers' risky on-road behaviours [16-18]. Thus, this pilot study sought to develop an appropriate method for the effective deployment of CBT techniques to reduce stress for motorcycle riders and potentially increase rider safety. To the authors' knowledge, CBT has not been studied in the specific context of motorcyclists stress and as such represents a novel contribution to a growing body of literature.

A brief CBT programme was developed incorporating elements of stress management and road safety, focused specifically on addressing feelings of anger, anxiety, and worry while on the road as well as on-road behavioural responses from participants dealing with stress. The programme was successfully delivered to five motorcyclists of different ages, motorcycle types, situational stressors, and riding experience. The research also included one female motorcyclist.

The findings from this exploratory study show that there is promise in employing CBT with motorcyclists to address stress that is associated with increased collision risk. Data from the DSI and DBQ showed small, but safe changes in participant's self-reported anger, dislike of (or anxiety about) riding, thrill seeking, and hazard monitoring. They also showed some reductions in participants' self-reported likelihood to engage in traffic violations and slips and lapses. Assessment of the case studies showed that scores on some subscales improved by up to 1.80 points from pre-intervention to post-intervention assessment. Although the data collected post-intervention only represented immediate feedback from participants (and one that was likely characterised by a process of consolidation of the programme achievements), this data supports the potential benefits of CBT with riders. Similarly, the qualitative data gathered through the rider log and the participant feedback showed that the intervention was well received and that participants were able to identify 
on-road scenarios where the techniques provided were useful in reducing the effects of otherwise stressful situations.

These findings demonstrate the potential value of CBT as a tool to improve road safety for motorcyclists dealing with stress and stress-related anxiety, anger, and worry. Not only has CBT been shown to be effective in treating anger and anxiety (e.g., $[20,21])$ and road-related behaviours in sub-groups of drivers such as bus and taxi drivers $[16,18]$ and military personnel (though the sample included persons with PTSD markers [17]), but it also fits in with the notion that road safety interventions need to consider individual differences, including vulnerabilities to common issues such as stress [11]. As Matthews and Dorn (1997) put it, the development of interventions requires a greater "fine-grained understanding of how drivers' coping strategies and appraisals of the traffic environment vary across individuals and situations" ([11], p. 146). CBT offers this finer level of understanding of the individual and uses this knowledge to work through everyday difficulties that may increase the risk of being involved in a collision.

Further research involving much larger samples of participants is required before additional recommendations about the potential application of CBT can be provided, particularly in terms of understanding how CBT could be rolled out effectively to at-risk populations. For the purpose of this research, riders had to self-identify as experiencing stressors that affected their riding; due to the nature of the recruitment (and a small incentive for participation), participants also had to be self-motivated to take part in the intervention. In the future (and if more robust evaluations showed the intervention showed reliable changes in attitudes and/or behaviours), the intervention could be provided to riders who commit particular offences (for example, as an alternative to points or fines) or to riders who are referred after being involved in a collision or near-collision. Similarly, the CBT intervention could also be evaluated for its effectiveness in aiding other road users who may be experiencing stress, and stress-related anxiety or anger. This could further expand the application of CBT and make the intervention available to other high-risk groups of road users.

Lastly, stress has been normalized as part of everyday life and as such there are wider challenges in gaining buy-in from the general population for introducing behavioural intervention of this kind. One positive outcome in applying CBT in road safety is that it could help to raise awareness of the possible impact of issues such as prolonged stress by highlighting the real-world links to health and safety outcomes.

\section{Limitations}

Despite the findings, it is recognised that this study had a small sample of participants and no control intervention against which to benchmark the CBT approach. Although the results indicate a potential safety benefit through lower risk on the DSI and DBQ scores, given the small sample involved in the work, these scales were used as a means to observe the changes in these measures that could be associated with the application of the CBT intervention, and hence the authors are not able to draw any conclusions about how these relate to wider group norms. In terms of the qualitative data, the rider log does not provide comparison of like-for-like situations experienced by participants; as such, it is limited in its ability to evidence change.

In addition, the five participants who completed the CBT programme were internally motivated to do so. This was exhibited by their willingness to commit to the six-week programme (regardless of the relatively small incentive provided for taking part), as well as by their ability to identify particular on-road behaviours (and/or cognitions) they wanted to improve on. It is clear that this might not be the case for other riders; in fact, many riders may view riding as a 'stress release'. This was the case with a number of the respondents who were initially invited to take part in the present study; although they were able to self-report life stressors and riding difficulties, they did not believe that these were related to (or affecting) their riding experience. As mentioned previously, it was beyond the scope of the present study to evaluate perceived versus actual riding behaviour and, as such, participants who were unable to identify life stressors were not shortlisted for the pilot. If applied more widely, 
this intervention would need to demonstrate a capacity to engage with different (less self-motivated) segments of the road user population; this could be achieved through referrals or, if provided, as an alternative to fines or points.

Another possible limitation is that the CBT intervention employed focused on the mitigation of stress in a context that was potentially unrelated to the source of the stress (i.e., on-road riding behaviours). However, this was based on evidence suggesting that stress, regardless of its aetiology, can have an impact on road safety [5-7]. Motorcyclists were considered to be an important group in this context as, although the literature relating to stress in a rider-specific domain is extremely limited, motorcyclists experience increased vulnerability not only due to the limited protection of the bike (compared to a car or van) but also due to exposure to weather and unfavourable road conditions (for example, heavy rain, wind, and/or low visibility). However, the CBT program would likely have to be modified for the treatment of particular stressors relating to on-road events (such as post-traumatic stress-PTSD—as a result of a collision). However, the aim of the present work was to mitigate the impact of stress in a non-clinical sample; the results of the work suggest that the course had some effectiveness within this context.

Although the key methodological limitations of the study have been discussed above, the research findings also suggested that not all participants reported improvements week on week (as evidenced by the rider log), and one participant even showed an increased thrill-seeking score at the post-intervention assessment (from 0.55 to 1.61). The participant did exhibit the expected direction of scores for the aggression and hazard monitoring subscales. However, this participant had recently been involved in an injury collision, and one of the concerns he identified at the beginning of the intervention was a loss of confidence while riding. It is possible that receiving the intervention led to an increase in confidence and, as a result of this, a small increase in his reported thrill-seeking behaviour.

\section{Conclusions}

The findings discussed in this paper suggest that CBT could be an effective intervention for motorcyclists experiencing stress, particularly when this is having an impact on their self-reported riding abilities. However, the present study is limited and further research should endeavour to replicate these findings with a larger sample of motorcyclists. Similarly, CBT could also be trialled with other at-risk populations, such as professional drivers who may be faced with additional stressors such as time pressure and fatigue.

Future research should also aim to understand the effectiveness of CBT above and beyond other, more widely available interventions (such as educational interventions and/or rider or driver training). This could help to further build a case for the wide-spread use of CBT in road safety. It would also be of interest to examine the durability of the CBT programme to determine how long before (if at all) levels of anxiety and stress returned to pre-intervention levels. This would facilitate understanding of the cost/benefit ratio of CBT in this context. Furthermore, it would be important to measure the interaction of feelings of anxiety with amount of motorcycling to ensure that any improvements in attitudes and behaviours when riding that are associated with CBT are not also associated with a significant increase in the amount of riding undertaken — which is known to be a higher risk road activity (e.g., [22]).

Lastly, future research could evaluate the effectiveness of a CBT programme delivered over different modes. For example, one of the limitations in the recruitment process involved the need for participants to attend face-to-face sessions with a practitioner. If the intervention was developed as an online tool (for example) this could help ensure the intervention is accessible by those who need it most, with a more realistic investment of time allowing the widespread use of such an approach.

This pilot study demonstrated a successful approach for the delivery of a CBT programme to a group of road users that are overrepresented in collision statistics, the results of which indicate potential for CBT to modify behaviours that could result in improved road safety. Whilst the study size limits the extent to which the results can be generalised, the method was applied effectively and has laid a foundation for future research on this topic. 
Acknowledgments: The authors would like to acknowledge the Institute of Advanced Motorists (IAM) RoadSmart, which funded the work undertaken. IAM RoadSmart is a charitable organization based in the United Kingdom. No additional funding was received for the purpose of publication. The authors would also like to acknowledge Samantha Danesh-Pour for her support in the development of the intervention and delivering the sessions that were instrumental to the completion of this work.

Author Contributions: K.F.-M. and N.R. conceived and designed the research; K.F.-M. undertook the study and analysed the data; K.F.-M. and N.R. wrote the paper.

Conflicts of Interest: The authors declare no conflict of interest. The funding sponsors had no role in the design of the study; in the collection, analyses or interpretation of data, or in the writing of the manuscript; they did, however, have a role in the decision to publish the results as TRL are not the sole owners of the data.

\section{References}

1. Health and Safety Executive. Work Related Stress, Anxiety and Depression Statistics in Great Britain 2015; Health and Safety Executive: Merseyside, UK, 2015.

2. McEwen, B.S. Central effects of stress hormones in health and disease: Understanding the protective and damaging effects of stress and stress mediators. Eur. J. Pharmacol. 2008, 583, 174-185. [CrossRef] [PubMed]

3. Elander, J.; West, R.; French, D. Behavioral correlates of individual differences in road-traffic crash risk: An examination of methods and findings. Psychol. Bull. 1993, 113, 279-293. [CrossRef] [PubMed]

4. Hill, J.D.; Boyle, L.N. Driver stress as influenced by driving maneuvers and roadway conditions. Transp. Res. Part F Traffic Psychol. Behav. 2007, 10, 177-186. [CrossRef]

5. Rowden, P.; Matthews, G.; Watson, B.; Biggs, H. The relative impact of work-related stress, life stress and driving environment stress on driving outcomes. Accid. Anal. Prev. 2011, 43, 1332-1340. [CrossRef] [PubMed]

6. Lagarde, E.; Chastang, J.F.; Gueguen, A.; Coeuret-Pellicer, M.; Chiron, M.; Lafont, S. Emotional stress and traffic accidents: The impact of separation and divorce. Epidemiology 2004, 15, 762-766. [CrossRef] [PubMed]

7. Legree, P.J.; Heffner, T.S.; Psotka, J.; Martin, D.E.; Medsker, G.J. Traffic crash involvement: Experiential driving knowledge and stressful contextual antecedents. J. Appl. Psychol. 2003, 88, 15-26. [CrossRef] [PubMed]

8. Fuller, R. Towards a general theory of driver behaviour. Accid. Anal. Prev. 2005, 37, 461-472. [CrossRef] [PubMed]

9. Cartwright, S.; Cooper, C.L.; Barron, A. The company car driver, occupational stress as a predictor of motor vehicle accident involvement. Hum. Relat. 1996, 49, 195-208. [CrossRef]

10. Matthews, G.; Dorn, L.; Glendon, A.I. Personality correlates of driver stress. Personal. Individ. Differ. 1991, 12, 535-549. [CrossRef]

11. Matthews, G.; Dorn, L.; Hoyes, T.W.; Davies, D.R.; Glendon, A.I.; Taylor, R.G. Driver stress and performance on a driving simulator. Hum. Factors J. Hum. Factors Ergon. Soc. 1998, 40, 136-149. [CrossRef]

12. Matthews, G. Towards a transactional ergonomics for driver stress and fatigue. Theor. Issues Ergon. Sci. 2002, 3, 195-211. [CrossRef]

13. Underwood, G.; Chapman, P.; Wright, S.; Crundall, D. Anger while driving. Transp. Res. Part F Traffic Psychol. Behav. 1999, 2, 55-68. [CrossRef]

14. Shahar, A. Self-reported driving behaviors as a function of trait anxiety. Accid. Anal. Prev. 2009, 41, $241-245$. [CrossRef] [PubMed]

15. Jonah, B.A. Sensation seeking and risky driving: A review and synthesis of the literature. Accid. Anal. Prev. 1997, 29, 651-665. [CrossRef]

16. Najeeb, P.M. Study of Effect of Cognitive Behavioural Therapy for Drivers Improvement. In Proceedings of the Australasian Road Safety Research Policing Education Conference, Adelaide, Australia, 10-12 November 2008.

17. Strom, T.; Leskela, J.; Possis, E.; Thuras, P.; Leuty, M.E.; Doane, B.M.; Wilder-Schaaf, K.; Rosenzweig, L. Cognitive-Behavioral Group Treatment for Driving-Related Anger, Aggression, and Risky Driving in Combat Veterans: A Pilot Study. J. Trauma. Stress 2013, 26, 405-408. [CrossRef] [PubMed]

18. Kazemeini, T.; Ghanbari-e-Hashem-Abadi, B.; Safarzadeh, A. Mindfulness Based Cognitive Group Therapy vs. Cognitive Behavioral Group Therapy as a Treatment for Driving Anger and Aggression in Iranian Taxi Drivers. Psychology 2013, 4, 638-644. [CrossRef]

19. McGinn, L.K.; Sanderson, W.C. What allows cognitive behavioral therapy to be brief: Overview, efficacy, and crucial factors facilitating brief treatment. Clin. Psychol. Sci. Pract. 2001, 8, 23-37. [CrossRef]

20. Butler, A.C.; Chapman, J.E.; Forman, E.M.; Beck, A.T. The empirical status of cognitive-behavioral therapy: A review of meta-analyses. Clin. Psychol. Rev. 2006, 26, 17-31. [CrossRef] [PubMed] 
21. Tyrer, P.; Cooper, S.; Salkovskis, P.; Tyrer, H.; Crawford, M.; Byford, S.; Dupont, S.; Finnis, S.; Green, J.; McLaren, E.; et al. Clinical and cost-effectiveness of cognitive behaviour therapy for health anxiety in medical patients: A multicentre randomised controlled trial. Lancet 2014, 383, 219-225. [CrossRef]

22. The Department for Transport (DfT). Reported Road Casualties Great Britain 2014; DfT: London, UK, 2015.

23. Knowles, J.; Smith, L.; Cuerden, R.; Delmonte, E. Analysis of Police Collision Files for Pedestrian Fatalities in London, 2006-10; The Transport Research Laboratory: Crowthorne, UK, 2012.

24. Helman, S.; Weare, A.; Palmer, M.; Fernandez-Medina, K. Literature Review of Interventions to Improve the Conspicuity of Motorcyclists and Help Avoid 'Looked but Failed to See' Accidents; Published Project Report (PPR638); Transport Research Laboratory: Crowthorne, UK, 2012.

25. Musselwhite, C.B.; Avineri, E.; Susilo, Y.O.; Bhattachary, D. Public attitudes towards motorcyclists' safety: A qualitative study from the United Kingdom. Accid. Anal. Prev. 2012, 49, 105-113. [CrossRef] [PubMed]

26. Bazargan-Hejazi, S.; Zamani-Alavijeh, F.; Hindman, D.; Mohamadi, E.; Bazargan, M. How do motorcyclists manage mental tensions of risky riding? BMC Public Health 2013, 13, 865. [CrossRef] [PubMed]

27. Christmas, S.; Young, D.; Cookson, R.; Cuerden, R. Passion, Performance, Practicality-Motorcyclists' Motivations and Attitudes to Safety-Motorcycle Safety Research Project; Project Report; TRL: Crowthorne, UK, 2009.

28. Matthews, G.; Desmond, P.A.; Joyner, L.; Carcary, B.; Kirby, G. A comprehensive questionnaire measure of driver stress and affect. Traffic Transp. Psychol. 1997, 317-324.

29. Reason, J.; Manstead, A.; Stradling, S.; Baxter, J.; Campbell, K. Errors and violations on the roads: A real distinction? Ergonomics 1990, 33, 1315-1332. [CrossRef] [PubMed]

30. De Winter, J.C.F.; Dodou, D. The Driver Behaviour Questionnaire as a predictor of accidents: A meta-analysis. J. Saf. Res. 2010, 41, 463-470. [CrossRef] [PubMed]

31. Helman, S.; Reed, N. Validation of the driver behaviour questionnaire using behavioural data from an instrumented vehicle and high-fidelity driving simulator. Accid. Anal. Prev. 2015, 75, 245-251. [CrossRef] [PubMed]

32. Kontogiannis, T. Patterns of driver stress and coping strategies in a Greek sample and their relationship to aberrant behaviors and traffic accidents. Accid. Anal. Prev. 2006, 38, 913-924. [CrossRef] [PubMed]

33. Parker, D.; Lajunen, T.; Stradling, S. Attitudinal predictors of interpersonally aggressive violations on the road. Transp. Res. Part F Traffic Psychol. Behav. 1998, 1, 11-24. [CrossRef]

(C) 2016 by the authors; licensee MDPI, Basel, Switzerland. This article is an open access article distributed under the terms and conditions of the Creative Commons Attribution (CC-BY) license (http://creativecommons.org/licenses/by/4.0/). 